\title{
AS DISPUTAS PELO CURRÍCULO E A RENOVAÇÃO DA ESCOLA PRIMÁRIA NOS ESTADOS UNIDOS NA TRANSIÇÃO DO SÉCULO 19 PARA O SÉCULO 20 \\ DOI: http://dx.doi.org/10.1590/2236-3459/56892
}

\author{
Rosa Fátima de Souza \\ Universidade Estadual Paulista, Brasil.
}

$\cos 80$

\begin{abstract}
Resumo
Este texto compreende um estudo sobre as disputas pelo currículo do ensino primário nos Estados Unidos, na transição do século 19 para o século 20. Em primeiro lugar são analisados os princípios da correlação e da concentração das matérias tal como foram propostos por Francis Parker e pelos herbartianos, especialmente, Charles McMurry e Frank McMurry. Na sequencia é examinado o deslocamento verificado no debate curricular a partir das proposições de Stanley Hall e John Dewey, que defendiam a reconfiguração do currículo tendo em vista a natureza e os interesses da criança.

Palavras-chave: educação norte-americana, história do currículo, história do ensino primário.
\end{abstract}

\section{DISPUTES FOR THE CURRICULUM AND THE RENEWAL OF THE PRIMARY SCHOOL IN THE UNITED STATES FROM THE 19TH CENTURY TO THE 20TH CENTURY}

\section{Abstract}

This text includes a study on the disputes for the primary school curriculum in the United States from the 19th century to the 20th century. Firstly, the principles of correlation and concentration of the subject such as the ones proposed by Francis Parker and the Herbartians, especially Charles McMurry and Frank McMurry, will be analyzed. Secondly, the displacement found on the curricular debate from Stanley Hall's and John Dewey's propositions defending the reconfiguration of the curriculum considering the nature and the child's interests will be analyzed.

Key-words: north-american education, history of the curriculum, history of elementary school.

\section{LAS DISPUTAS POR EL CURRÍCULO Y LA RENOVACIÓN DE LA ESCUELA PRIMARIA EN ESTADOS UNIDOS EN LA TRANSICIÓN DEL SIGLO 19 PARA EL SIGLO 20}

\section{Resumen}

Este texto comprende un estudio sobre las disputas por el currículo de la enseñanza primaria en Estados Unidos en la transición del siglo 19 para el siglo 20. En primer lugar son analizados los 
principios de la correlación y de la concentración de las materias tal como fueron propuestos por Francis Parker y por los herbartianos, especialmente, Charles McMurry y Frank McMurry. En la secuencia, es examinado el desplazamiento verificado en el debate curricular desde las proposiciones de Stanley Hall y John Dewey defendiendo la restructuración del currículo teniendo en cuenta la naturaleza y los intereses del niño.

Palabras-clave: educación norteamericana, historia del currículo, historia de la enseñanza primaria.

\section{LES CONFLITS POUR LE CURRICULUM ET LE RENOUVELLEMENT DE L'ECOLE PRIMAIRE AUX ETATS-UNIS AU TOURNANT DES 19E ET 20E SIECLES}

\section{Résumé}

Ce texte comprend une étude sur les conflits envers le curriculum des études primaires aux EtatsUnis au tournant des $19 \mathrm{e}$ et $20 \mathrm{e}$ siècles. Tout d'abord, les principes de la corrélation et la concentration des matières, tels que proposés par Francis Parker et les Herbartiens, en particulier Charles McMurry et Frank McMurry. Ensuite, on examine le déplacement vérifié au débat scolaire dès les propositions de Stanley Hall et John Dewey défendant la reconfiguration du curriculum en vue de la nature et de l'intérêt de l'enfant.

Mots-clé: histoire de l'éducation américaine, histoire du curriculum, histoire de l'école primaire. 


\section{Introdução}

$\mathrm{O}$ objetivo deste texto é apresentar ao público brasileiro as principais proposições e concepções sobre o currículo do ensino primário em disputa presentes no debate educacional norte-americano no final do século $19 \mathrm{e}$ início do século 20 colocando em evidência como, nos Estados Unidos, a busca dos educadores por novos princípios de ordenação das disciplinas escolares reconfigurou a alquimia da racionalização curricular tornando-a mais abrangente, mais científica e fundamentada em dispositivos de poder mais incisivos.

De fato, a discussão sobre o que ensinar na escola primária fez parte da agenda educacional dos Estados Unidos durante o século 19. No entanto, como assinala Kliebard (1995), nas décadas finais desse século a seleção cultural para a educação elementar e secundária tornou-se alvo de acirradas disputas e esteve no centro de um efervescente debate sobre as finalidades e rumos da educação.

No ensino secundário a definição dos conteúdos tornou-se o ponto nevrálgico da discussão sobre a democratização do ensino. A disputa envolveu, inicialmente, os humanistas, defensores da manutenção de uma cultura clássica, representada, especialmente, pelo ensino das línguas Latim e Grego, os partidários do ensino científico de caráter mais prático e os que advogavam a diferenciação social do currículo tendo em vista as diferenças individuais e sociais e as demandas da sociedade urbano-industrial.

Em relação ao ensino primário também estiveram em disputa diferentes projetos de sociedade, mas o debate incidiu, sobretudo, nos princípios de ordenação curricular, envolvendo as abordagens científicas da educação emergentes e novas concepções sobre a criança, o ensino e o currículo. A questão da correlação dos estudos foi um dos aspectos sobre o qual os educadores polemizaram. Ela foi defendida pelos herbartianos, que nas décadas de 1880 e 1890 se consagraram como a vanguarda do pensamento científico em educação e também por Francis Parker, cujos trabalhos na direção da Quincy School foram marcados pela busca da inovação educacional.

No mesmo período destaca-se, ainda, a projeção do movimento Child-study, liderado por Stanley Hall, com as suas investigações sobre o desenvolvimento infantil e a consagração da Psicologia Experimental, juntamente com as primeiras proposições polêmicas de John Dewey sobre a educação nova.

Para os estudiosos norte-americanos a década de 1890 foi um divisor de águas na história do país. O período é destacado pela intensificação, sem precedentes, do desenvolvimento econômico, social e científico. Em realidade, muitos autores norteamericanos utilizam o termo Era Progressiva para designar o período histórico entre 1880 e 1920, caracterizado pela reorganização social e racionalização da vida pública em razão das transformações econômicas e sociais em larga escala, isto é, a aceleração do processo de urbanização e industrialização. Nesse período destacam-se a 
profissionalização do conhecimento científico na área das Ciências Humanas e a utilização desse conhecimento pelo poder público e pela classe média para a implementação de projetos de reforma social. ${ }^{1}$

O clima de efervescência cultural e econômica afetou também o campo educacional, motivando reformas e confrontos entre educadores, intelectuais e diferentes grupos sociais em disputa por um projeto educacional adequado para uma nova era.

O método intuitivo, tão proeminente até a década de 1870, foi caindo em desuso no discurso educacional norte-americano, substituído por concepções consideradas mais científicas, especialmente pela difusão das ideias de Herbart e a constituição da Psicologia como campo de conhecimento. As Lições de coisas foram consideradas uma posição ultrapassada vinculada a concepções educacionais românticas postuladas por pensadores como Pestalozzi, Rousseau, entre outros.

A inovação educacional desse período redescobriu a criança. A premissa $A$ criança é o centro de toda a educação foi afirmada por Francis Parker e a ele fizeram coro eminentes intelectuais e educadores como os herbartianos Charles De Garmo e os irmãos Charles e Frank McMurry, além de outros intelectuais, como G. Stanley Hall e John Dewey. Embora a consideração da criança fosse comum a todos eles, no decorrer da década de 1890 foram se delineando as diferenças de posições e as disputas pela hegemonia no campo educacional.

A racionalização do currículo da escola primária, iniciada em meados do século 19 com a implantação das escolas graduadas, ganhou novos contornos e maior refinamento teórico e conceitual. A correlação de estudos, entendida como um princípio de relação entre as disciplinas escolares, se impôs como um dispositivo curricular importante na redefinição da organização pedagógica das escolas, no governo das crianças e no controle da prática docente. Como afirmou Charles de Garmo (1895), o que estava em jogo na definição do currículo da escola primária era mostrar como o conhecimento obtido pelas crianças poderia ser utilizado. Importava, pois, precisar qual era a natureza, o tempo necessário e a ordem a ser estabelecida na organização dos conteúdos de ensino.

Interrogar sobre a proeminência do debate em torno da organização do currículo para as escolas primárias nos Estados Unidos no alvorecer do século 20 é relevante para se compreender a História da Educação e a emergência do currículo como área de conhecimento nesse país.

Além dessa finalidade o aprofundamento sobre o tema reveste-se de especial importância para os historiadores da educação no Brasil, uma vez que a referência educacional norte-americana foi amplamente difundida neste país na transição do século 19 para o século 20, justificando reformas educacionais nos Estados e servindo de

\footnotetext{
${ }^{1}$ Apesar de ser bastante utilizado na historiografia da educação norte-americana, o termo educação progressiva é controverso e aplica-se a diferentes interpretações do movimento educacional compreendido entre o final do século 19 até meados do século 20. Um dos primeiros historiadores a utilizarem o termo foi Lawrence Cremin na obra The transformation of the school: progressivism in american education (1876-1957), publicada em 1962. Para Cremin, a educação progressiva compreendia um esforço de usar as escolas para melhorarem a vida dos indivíduos. O progressivismo na educação implicava, portanto, uma fé radical na democratização da cultura. Autores como Cuban (1984) utilizam o termo educação progressiva como sinônimo de educação nova ou instrução centrada na criança. 
argumento para a renovação pedagógica. ${ }^{2}$ Dessa maneira, o olhar para a educação norte-americana contribui para um melhor entendimento sobre a circulação e apropriação de modelos educacionais.

O texto discorre sobre os princípios da correlação e da concentração das matérias tal como foram propostos por Francis Parker e pelos herbartianos, especialmente, Charles McMurry e Frank McMurry. Em torno desses princípios foi se configurando um conjunto de saberes sobre as disciplinas e sobre a ordenação do currículo do ensino primário com implicações importantes para a organização pedagógica das escolas. Em seguida assinala-se o deslocamento verificado no debate curricular a partir das proposições de Stanley Hall e John Dewey, que defendiam a reconfiguração do currículo tendo em vista a natureza e os interesses da criança.

Para a realização deste estudo foram utilizadas fontes encontradas no Center for Instructional Material \& Computing da Biblioteca da School of Education da University of Wisconsin e nos acervos da Memorial Library dessa mesma universidade. As fontes compreenderam manuais didáticos que tiveram grande repercussão nos cursos de formação de professores nos Estados Unidos: Talks on pedagogics: an outline of the theory of concentration (1894) de Francis Parker, representante do movimento de renovação educacional no final do século 19, e The elements of general method based on the principles of Herbart (1893) e Course of study in the eight grades (1906), ambos de Charles McMurry, um dos principais representantes do herbartianismo nos Estados Unidos. Nesses manuais a discussão curricular desenvolveu-se em torno da categoria concentração de estudos: a nova versão científica da racionalização curricular. O livro de John Dewey The child and the curriculum também foi utilizado pela sua importância no debate curricular do período.

$\mathrm{Na}$ elaboração deste texto intentamos estabelecer o diálogo com os autores norteamericanos que investigaram a história do ensino primário e a história do currículo nos Estados Unidos. Sobre essa bibliografia vale tecer algumas considerações. São poucos os estudos sobre a institucionalização da escola primária nesse país, referente ao século 19. Os estudos de Kaestle $(1970,1999)$ e Tyack (2000) são particularmente interessantes pela abrangência e pela abordagem sócio-histórica enfatizando as iniciativas políticas e organizacionais na constituição do sistema público de ensino. Filkestein (1989), embora descreva as práticas de sala de aula entre 1820 e 1880, atem-se aos papéis desempenhados pelos professores na época e Cuban (1984) analisa as práticas docentes, ensino centrado no professor versus ensino centrado no aluno, no período entre 1890 e 1980. O livro de Tyack e Cuban, Tinkering toward utopia: a century of public school reform (1995), também consiste em uma referência relevante pela forma como os autores problematizam as reformas educacionais questionando o problema da continuidade e mudança na educação estadunidense ao longo do século 20.

A História do Currículo emergiu nos Estados Unidos como área de estudos na década de 1950, no bojo do movimento de revisão crítica da História da Educação. Na maioria dos estudos predomina a consideração do currículo como campo de conhecimento e a busca de interpretação do porque certas ideias curriculares ou formas de pensamento sobre o currículo foram priorizadas em determinadas épocas. A

${ }^{2}$ Estudo aprofundado sobre o americanismo pode ser encontrado em Warde $(2000,2012)$. Hist. Educ. [Online] Porto Alegre v. 20 n. 48 Jan./abr., 2016 p. $35-53$ 
bibliografia é vasta e podem ser destacados os seguintes autores: Kliebard (1992), Pinar (1995), Franklim (1986). Herbert M. Kliebard (1995), no livro The struggle for the american curriculum (1893-1958), é um interlocutor privilegiado neste texto por ser um dos poucos pesquisadores a trabalhar de forma aprofundada e sistemática sobre o debate curricular século 19 e início do século 20. Neste livro, Kliebard põe em destaque os sujeitos educacionais envolvidos no debate e reconstitui os grupos de interesse em luta pelo currículo relacionando concepções curriculares com as forças políticas e sociais em jogo ${ }^{3}$.

Outros autores citados neste texto oferecem informações relevantes para a compreensão de questões específicas como o tema do progressivismo (Cremin, 1961; Krug, 1969) e do herbartianismo (De Garmo, 1895; Dunkel, 1970; Baker, 2001).

\section{A correlação das matérias como dispositivo de ordenação curricular}

Entre 1830 e 1860 um grupo de intelectuais e educadores norte-americanos buscou implantar o sistema público de ensino no país - common school system. Além da implantação da escola graduada nos centros urbanos, líderes educacionais como Henry Barnard, Horace Mann, entre outros, buscaram disseminar no país o pensamento pedagógico inovador em circulação nos países europeus, especialmente, as ideias de Pestalozzi e Froebel. Eles buscaram também adotar novos processos de organização pedagógica da escola primária fundamentados em padrões de eficiência, racionalidade e uniformização. Como têm assinalado Kastle (1999), Tyack (2000) e Filkestein (1989), a escola primária difundida nos Estados Unidos foi caracterizada pela valorização do nacionalismo, do patriotismo, da república, da democracia e do desenvolvimento econômico e social.

A expansão do sistema público de ensino ocorreu marcada pela variedade de instituições e o atendimento diferenciado dos diversos grupos étnico-sociais. Não obstante, representações construídas dentro e fora dos Estados Unidos buscaram exaltar os traços de modernidade que atestavam o progresso do país. Internamente, a Exposição Universal de Filadélfia, realizada em 1876, foi um marco da consagração desse desenvolvimento educacional. No plano externo, relatórios como os de Hippeau (1872) e de Buisson (1878) constituíram-se em estratégias discursivas importantes para propagandear internacionalmente os avanços da educação nos Estados Unidos e consolidá-la como referência modelar para vários países nas décadas finais do século $20^{4}$.

Ao longo do século 19 a ampliação dos programas do ensino primário acompanhou a ampliação das finalidades sociais atribuídas à educação popular nos Estados Unidos. Os saberes elementares - leitura, escrita e cálculo - passaram a ser considerados insuficientes para preparar as novas gerações para viverem em sociedades modernas, urbanizadas e industrializadas. Face à ampliação da seleção cultural tornou-se necessária a constituição de novos dispositivos de ordenação curricular. Emergia uma nova

\footnotetext{
${ }^{3}$ No conjunto da produção sobre a história do currículo destacam-se também investigações sobre a história das disciplinas escolares, especialmente do ensino secundário, como as obras de Popkewitz (1987); Kliebard (1992), entre outros.

${ }^{4}$ A Exposição Universal de Filadélfia foi realizada em 1876 em comemoração ao Centenário da Independência dos Estados Unidos. Nela os norte-americanos tiveram a oportunidade de dar visibilidade a seu sistema educacional apresentando-o como marca irrefutável de seu grau de civilização e progresso.
} 
exigência, isto é, a de unificação dos programas. Por isso, junto com o debate sobre o que ensinar nas escolas primárias, floresceu a discussão sobre os princípios de ordenação dos conteúdos. Não por acaso, tal debate foi desencadeado no interior dos estudos científicos da educação, que se tornaram a base de legitimação de posições conflitantes sobre a criança, a escola e o currículo.

As preocupações pedagógicas de Francis Parker são denotativas da relevância assumida pela discussão sobre planos de ensino e currículo no final do século 19.

O trabalho realizado por esse educador, como superintendente das escolas de Quincy-Massachusetts (1873-1880), Ihe proporcionou visibilidade nacional. Nas escolas de Quincy ele mudou o currículo, os métodos de instrução e os materiais de ensino. Em poucos anos Quincy tornou-se referência para os educadores interessados na educação nova. Os métodos de ensino adotados por Parker davam ênfase à experiência imediata das crianças, ao significado das atividades escolares e à adaptação do currículo ao desenvolvimento infantil. Cremin (1961) descreve as mudanças realizadas por Parker nos sistemas de Quincy da seguinte forma:

O currículo estabelecido foi abandonado e com ele a soletração, a leitura, a gramática e o caderno de cópia. As crianças eram iniciadas na leitura pelas palavras e sentenças simples mais do que pelo alfabeto aprendido pela repetição. No lugar de textos clássicos, revistas, jornais e materiais planejados pelos próprios professores foram introduzidos nas salas de aula. Aritmética era abordada indutivamente, através de objetos mais do que por meio de regras, enquanto geografia iniciava com uma série de viagens por diversas localidades do interior do país. Desenho era acrescentado para encorajar a destreza manual e a expressão individual. Ênfase era dada à observação, à descrição e à compreensão e somente quando essas habilidades manifestavam-se por si só - entre as faculdades mentais e entre os estudantes - as matérias convencionais eram introduzidas. (Cremin, 1961, p. 129)

Em 1880 Parker deixou Quincy e foi trabalhar como diretor da escola normal de Cook County, Illinois, onde formulou suas teorias educacionais com base em dois pressupostos: a criança como centro do processo educativo e a inter-relação das matérias do currículo de forma a terem significado para a criança. Em Quincy, Francis Parker publicou dois livros importantes: Talks on teaching (1883) e Talks on pedagogics: an outline of the theory of concentration (1894). Considerado por Cremin (1961) como o primeiro tratado de pedagogia norte-americano a ganhar reconhecimento internacional, Talks on pedagogics trazia como inovação o modo como o autor fundamentava sua obra na concepção de método de Pestalozzi, na concepção de criança de Froebel e na doutrina da concentração de Herbart produzindo uma síntese que se constituía para ele em uma teoria científica da educação.

O modo peculiar pelo qual o autor se apropriou dos conceitos de concentração e correlação de Herbart permite entrever como a organização pedagógica da escola elementar, o currículo e a criança tornaram-se objetos de conhecimento e tecnologias de poder no campo educacional. Para Parker (1894) a doutrina da concentração consistia no ponto de partida do esforço de se organizar o currículo da escola primária colocando a criança no centro do processo. Isso significava considerar que era o ser em desenvolvimento que determinava quais conteúdos e quais métodos deveriam ser 
utilizados na educação. Dessa maneira, a doutrina da concentração compreendia em si mesma uma ciência da educação. O desenvolvimento infantil era o primeiro aspecto a ser considerado na organização do currículo. Em segundo lugar era preciso unificar os conteúdos em torno de algumas matérias, por exemplo:

(a) Geografia, geologia e mineralogia - as ciências da matéria inorgânica.

(b) Física e Química - as leis do movimento e da mudança da matéria inorgânica. (c) Botânica, zoologia, antropologia, etnologia e história - as ciências da vida orgânica. (d) Fisiologia - a física e a química dos organismos vivos. (Parker, 1894, p. 377)

A teoria da concentração propunha que as matérias pudessem ser estudadas conforme as crianças entravam em contato com elas. Parker destacava a linguagem oral, a leitura, os exercícios físicos, a música e a formação moral como aspectos fundamentais para o desenvolvimento. Mas o problema estava em definir o que era fundamental ensinar para as crianças e qual seria o programa de estudos ideal. Para Parker a resposta consistia em desenvolver a educação pelo crescimento harmonioso entre corpo, mente e alma: "A criança permanece no centro do círculo; em torno dela está o universo ambiental, o homem e a natureza" (Parker, 1894, p. 387).

O educador defendia, pois, um currículo amplo para a escola primária e dizia que o problema não estava na quantidade de matérias, mas na qualidade da ação mental. Para a aplicação da doutrina da concentração era necessária a arte de ensinar, o que dependia, portanto, de um trabalho diferenciado do professor. Um ensino qualitativo implicava conhecer o caráter de cada aluno e seu desenvolvimento mental, selecionar no programa de ensino os conteúdos imediatamente necessários para o avanço dos poderes mentais e morais, estudar continuamente cada criança e amá-la. Para tanto, o professor deveria ser sempre um estudante entusiasta da educação. A teoria indicava a atenção constante do professor para a relação entre as matérias e igual atribuição de valor a todas elas: "O aspecto mais encorajador da concentração é que ela demanda o estudo persistente de todas as matérias e a prática em todos os modos de expressão por parte dos professores efetivos"(Parker, 1894, p. 397).

Envolvido com os desafios postos pelas urgências do cotidiano, fossem os da formação de professores, fossem os da prática educativa dos docentes nas escolas primárias, Francis Parker procurou oferecer alternativas para o problema do desenvolvimento do programa enciclopédico de ensino. Para além da questão do que ensinar nas escolas impunha-se como distribuir esse conteúdo em unidades e lições, e como adequar essa distribuição aos pressupostos da Psicologia emergente.

Francis Parker, sendo professor do ensino primário e normal, obteve projeção nacional em um período em que a profissionalização do conhecimento em educação passava para o domínio das universidades e outras instituições de ensino superior (Krug, 1969; Kliebard, 1995; Pinar, 1995).

Foi atendendo à solicitação de Francis Parker em 1893 que a National Educational Association indicou um comitê para discutir a correlação de estudos e elaborar uma proposta curricular para o ensino elementar. O denominado Committee of Fifteen, liderado por William Torry Harris, produziu um relatório intitulado Report on the correlation of studies in elementary education reafirmando posições humanistas e deflagrando um dos 
mais importantes debates sobre currículo e sobre a educação norte-americana no final do século 19, marcando, dessa forma, o realinhamento de forças e os grupos de interesse em relação ao currículo (Kliebard, 1995). Correlação tornou-se um conceito educacional importante nos Estados Unidos no final do século 19. Contudo, as ideias de Herbart fundamentaram posições antagônicas como a dos herbartianos e a do movimento Childstudy. Esses dois grupos distanciaram-se das proposições de Francis Parker e buscaram reconfigurar o discurso sobre a criança e o currículo em novas bases.

\section{A racionalização curricular proposta pelos herbartianos norte-americanos}

Charles De Garmo, Charles McMurry e Frank McMurry são considerados os principais representantes do herbartianismo nos Estados Unidos. Charles De Garmo publicou The essentials of method em 1889 e Herbart and the herbartians em 1895. Charles McMurry publicou a primeira edição de The elements of general method based on the principles of Herbart em 1892, Course of study in the eight grades em $1906 \mathrm{e}$, junto com seu irmão, Frank McMurry, a obra Method of the recitation em 1897. Segundo Dunkel (1970), esses livros introduziram o pensamento de Herbart para os profissionais da educação norte-americanos e as obras e as atividades desses três homens repercutiram na formação dos professores e influenciaram muitos educadores. Os três autores, formados pela State Normal School de Illinois, estudaram, em Jena, os desdobramentos das ideias de Herbart desenvolvidas por Wilhelm Rein e Ziller ${ }^{5}$ e teriam adotado dois aspectos do pensamento de Ziller: primeiro a concepção de centros de concentração como estratégia para a organização dos conteúdos de ensino.

Em segundo lugar, a culture-epoch theory, isto é, a ideia segundo a qual a ontogênese recapitulava a filogênese, em outros termos, a história do desenvolvimento de um indivíduo repete a evolução da espécie. A atração dos educadores por esta teoria no final do século 19 é explicada por Pinar (1995) tendo em vista três motivos: tratava-se de uma teoria da história e a história era considerada a disciplina com o maior potencial para o desenvolvimento do caráter da criança; pensava-se que a teoria da época cultural pudesse facilitar a integração entre as disciplinas escolares, podendo as épocas históricas, neste sentido, servir como centro de concentração do currículo; os princípios clássicos e psicológicos de ordenação das disciplinas escolares estavam sendo criticados na época e a concentração dos estudos defendida pelos herbartianos oferecia uma opção alternativa.

Os herbartianos fundaram o Herbart Club em 1892. Três anos depois a sociedade mudou de nome para National Herbart Society. John Dewey chegou a participar da sociedade mesmo discordando de algumas de suas posições (Kliebard, 1995). Em 1900 a sociedade passou a se denominar National Society for the Scientific Study of Education (1900-1908), e, em 1909, mudou novamente para National Society for the Study of Education. O herbartianismo como um movimento com identificação específica teve uma

\footnotetext{
${ }^{5}$ Como assinala Dunkel (1970), o revivamento do pensamento de Herbart deve-se a Tuiskon Ziller, com a publicação de Foundation of the doctrine of educative instruction. O herbartianismo floresceu especialmente, depois de 1885, quando Wilhelm Rein, aluno de Ziller, tornou-se diretor do Seminário Pedagógico de Jena. Este seminário passou a ser considerado referência na difusão do pensamento pedagógico inovador e a obra de Herbart foi traduzida para várias línguas na Europa, tornando-se reconhecida internacionalmente. 
vida curta na educação norte-americana entrando em declínio por volta de 1905, mas, como sublinham vários autores, suas ideias e reações a elas continuaram a exercer profunda influência no currículo desse país (Cremin, 1961; Krug, 1969, Kliebard, 1995, Baker, 2001).

$\mathrm{Na}$ sequencia deste texto analisamos algumas concepções e proposições dos herbartianos norte-americanos para o currículo do ensino primário, tomando como base o exame de alguns livros destinados à formação de professores publicados por eles.

No livro Herbart and the herbartians Charles De Garmo (1895) priorizou os elementos que justificavam uma posição determinada no debate sobre o currículo, isto é, a teoria da época cultural e os conceitos de concentração e correlação das matérias. Na opinião do autor, o que Pestalozzi teria deixado para Herbart fazer teria sido dar à educação uma base científica. Embora Comenius, Rosseau e Pestalozzi houvessem firmado a convicção de que a observação, o uso dos sentidos e o princípio de partir do fato concreto fossem a fundamentação segura para o ensino elementar, esses autores não haviam detalhado de forma clara e eficiente como deveria ser organizado o programa de ensino. Nesse sentido, Charles De Garmo afirmava que,

em síntese, não mostraram como a assimilação mental poderia ocorrer melhor ou como as aquisições resultantes poderiam se tornar mais eficientes para influenciar o lado emocional e motivacional de nossa natureza. Percepção é, de fato, o primeiro estágio da cognição, mas é igualmente importante correlacionar a percepção ou a assimilação mental. (De Garmo, 1895, p. 7)

Ainda na concepção do autor, a coordenação das matérias era fundamental tendo em vista a discussão sobre as necessidades da educação para uma nova era, uma vez que cabia à escola formar o aluno para a vida do homem de negócios. Nessa direção, argumentava a favor da introdução no currículo da ideia de economia, "não somente como um princípio influenciando a escolha e perpassando todo o conhecimento, mas também como um centro distinto para um importante grupo de atividades escolares." (De Garmo, 1895, p. 242). Propunha, assim, diferentes centros de unificação do currículo: o grupo dos estudos humanísticos centrados na literatura e na história em conformidade com a doutrina da época cultural, o grupo de estudos da natureza e um terceiro grupo tendo como eixo a economia promovendo a intersecção entre o homem e a natureza por meio de matérias como trabalhos manuais, arte industrial, desenho mecânico e geografia comercial.

Os herbartianos valeram-se dos conceitos de concentração e correlação para propor novas bases para a organização do currículo. Concentração significava o agrupamento de todas as matérias do currículo em torno de um tema central comum, por exemplo, um tema da História ou da Literatura. A correlação acompanhava a concentração cuidando para que cada tópico do programa de ensino estudado recebesse apoio integral de todos os demais tópicos. 
No livro de Charles McMurry, The elements of general method based on the principles of Herbart, é possivvel perceber a profundidade da reorientação do discurso em torno da organização curricular protagonizada pelos herbartianos. ${ }^{6}$ Para esse autor era imprescindível problematizar o valor relativo das diferentes matérias nos programas de ensino tendo em vista o objetivo primordial da educação de desenvolvimento da cultura moral. Essa finalidade se justificava por vários motivos: os hábitos morais proporcionavam melhor qualidade de vida e ativavam o caráter; as crianças podiam ser formadas para a vida em sociedade e para a cidadania; as ideias morais estavam presentes em vários tipos de conhecimentos; a escola se constituía em uma organização social e as crianças não podiam estar nela sem praticarem as virtudes sociais, dentre outros.

Reconhecia, portanto, que a diversificação dos programas era um fato incontestável na educação norte-americana. Ao longo das últimas décadas haviam sido introduzidas novas matérias como história, desenho, ciências naturais, trabalhos manuais, literatura moderna e cultura física, além das habilidades de leitura, escrita e cálculo. A ampliação dos programas acarretara inúmeros problemas, entre eles, a má qualidade do ensino de algumas matérias e a falta de relação entre os conteúdos.

Do ponto de vista de Charles McMurry, os professores ainda preferiam lidar com os programas formais privilegiando determinadas matérias em detrimento de outras, e isso ocorria, em parte, pelo prevalecimento entre eles da convicção na doutrina da disciplina mental, isto é, a crença generalizada de que a educação consistia na disciplina e no adestramento da mente.

Para resolver o problema o autor propunha a correlação das matérias: "O caráter superficial e embaralhado do nosso programa atual deveria dar lugar, pelo significado do ajustamento próprio e da interconexão entre as matérias, a uma unidade forte e profunda que nós ainda não encontramos" (McMurry, 1903, p. 25).

Para discutir a validade das matérias do programa de ensino, o autor dividia-as em três classes: História: biografia, história, literatura; Ciências naturais e Estudos formais: gramática, escrita e aritmética. As duas primeiras classes - História e Ciências Naturais abriam o campo para o real conhecimento de experiências, do mundo do homem e da natureza externa. Devido à teoria da época cultural, os herbartianos norte-americanos deram grande ênfase ao ensino de História. McMurry sugeria o uso extensivo de materiais históricos e literários em todas as séries, com o consciente propósito de modelar o caráter das crianças mediante a transmissão de ideias morais. Para ele, a História consistia, pois, na disciplina mais importante do currículo e sua relevância era assim justificada:

A História, em seu sentido amplo e liberal, deveria ser um influente constitutivo da educação da criança. Esta matéria que contém a essência da cultura moral em sua forma produtiva merece constituir o principal alimento mental dos jovens. A convicção no alto valor moral dos conteúdos históricos e sua peculiar adaptabilidade para as crianças de diferentes idades leva-nos a um julgamento positivo dessa matéria em relação a

\footnotetext{
${ }^{6}$ A primeira edição desse livro é de 1892. Para a análise efetuada neste texto estamos considerando a edição revista e ampliada publicada em 1903. 
todas as outras. A primeira questão, preliminarmente a tudo o mais na escola primária comum, 'qual é a material mais importante? É respondida colocando o estudo do homem na história e a literatura como os primeiros da lista. (Mcmurry, 1903, p. 50)

Em segundo lugar viriam as Ciências Naturais que poderia envolver o estudo da vida das plantas e animais, minerais, aparelho físico, experimentos químicos, a elaboração de coleções, excursões regulares para a observação dos campos vizinhos, florestas e o trabalho sobre experiências concretas.

Em terceiro lugar viriam os Estudos Formais: leitura e escrita. Para C. McMurry eles constituíam parte indispensável, mas deveriam ocupar um lugar secundário no programa de ensino, porque se atinham mais à forma do que ao conteúdo da ciência. Dessa maneira reafirmava sua oposição à prática dos estudos formais no centro dos programas subordinando tudo mais a eles, enquanto: "História e ciências naturais, ao contrário, possuindo o mais rico conteúdo, constituem o centro natural para todos os esforços educativos" (C. Mcmurry, 1903, p. 83).

Charles McMurry deteve-se na análise minuciosa dos conceitos de correlação e concentração no livro The elements of general method based on the principles of Herbart. Por correlação de estudos, entendia "a conexão entre as partes de cada matéria e as conexões entre as diferentes ciências cuja unidade poderia emergir de uma variedade de conhecimentos" (C. Mcmurry, 1903, p. 162). O oposto da correlação era o isolamento praticado nas escolas onde cada matéria era ensinada separadamente. Ainda segundo o autor, a

correlação busca superar a presente desconexão das matérias, ela enfatiza a relação e busca ampliar o âmbito da atenção e do exame racional do pensamento da criança, sua auto atividade e discernimento, pelo planejamento e pela disposição das matérias no programa de ensino, de tal maneira que as ciências possam ser trazidas em todo lugar numa justaposição mais vital, a fim de que o conhecimento da criança possa ser unificado e o seu poder prático sobre ele aumentado. (C. Mcmurry, 1903, p. 164)

O conceito de concentração, por sua vez, não apenas enfatizava as inter-relações entre as matérias, mas supunha a dependência de uma matéria em relação à outra:

Em um extremo pode ela estabelecer uma matéria ou um grupo de matérias no centro do currículo, e, concentrar todas as outras matérias ou grupos de matérias em relações mais ou menos subordinadas em volta desse centro. [...] A sequencia de tópicos na matéria subordinada pode ser determinada, até certo ponto, pela matéria central. A quantidade dessa subordinação depende do plano geral disposto no programa de ensino. (C. Mcmurry, 1903, p. 166)

Havia, pois, várias formas diferentes pelas quais a correlação podia ser alcançada: primeiro pela conexão das ideias entre matérias próximas. Isso era fundamental uma vez que muitos professores não admitiam que cada lição pudesse ser uma coleção de fatos conectados. Em realidade, prevalecia entre os professores do ensino primário a ideia de 
existência de uma ordem científica natural, ou seja, uma sequência de tópicos que acompanhava a estrutura de uma ciência, obedecendo a uma lógica indutiva, partindo do simples para o complexo.

Em segundo lugar a correlação preocupava-se com a relação de diferentes matérias uma com a outra, o que significava reconhecer o grande número de relações existentes entre diferentes ramos do conhecimento.

Observar as leis da associação era fundamental, pois o mais importante consistia em ensinar bem poucos conhecimentos de forma a atingir o objetivo primordial da educação que era a formação do caráter dos alunos. Nesse sentido, o autor se defendia das críticas feitas aos herbartianos por não reconhecerem o valor do conhecimento científico. Rebatia afirmando que a verdadeira finalidade de todo ensino estava em fazer a criança compreender melhor o mundo dos homens e as coisas em torno dela. Por isso, não via conflito entre os planos de correlação das matérias e a classificação das ciências, pois o mais importante não estava na quantidade de conteúdo transmitido pelas escolas, mas na relação que os alunos podiam fazer das ideias fundamentais ensinadas.

$\mathrm{Na}$ visão de Charles McMurry a multiplicação das matérias exigia o bom emprego do tempo e a correlação dos conteúdos produzia economia de esforços. Essa busca de racionalidade do programa de ensino vinha ao encontro dos problemas vivenciados pelos professores nas escolas e isso pode explicar o sucesso que o livro de Charles McMurry obteve entre os professores. Conforme assinala Dunkel (1970), ele foi utilizado nas escolas normais dos Estados Unidos como livro didático na formação de professores e em apenas três anos chegou à $5^{a}$ edição. Nos anos seguintes o autor, junto com Frank McMurry, dedicou-se à publicação de oito volumes intitulados Special method abarcando diferentes matérias do ensino primário. Em 1906, Charles McMurry publicou, em dois volumes, uma proposta de programa de ensino para a escola elementar intitulada Course of study in the eight grades. Nesses livros, abordou de forma minuciosa o problema central da organização de um programa de ensino levando-se em conta os princípios da teoria social e psicológica de Herbart. Ele buscou responder às seguintes questões:

Como podemos simplificar e organizar essas matérias de modo a assegurar satisfatoriamente 0 conhecimento $e$ a disciplina sem desconsiderar as matérias essenciais? Como conciliar as necessidades do crescimento infantil com as demandas da sociedade, de modo que as crianças possam entrar na vida madura completamente equipadas? (C. Mcmurry, 1906, p. 16)

Novamente o autor assinalou a economia como sendo uma das vantagens de um bom programa de ensino, isto é, a capacidade de determinar objetivos simples que pudessem controlar o trabalho dos professores. O programa de ensino deveria contribuir para reduzir perdas, eliminar o não essencial, focar nas ideias principais e oferecer indicações precisas para a simplificação e racionalização do ensino nas escolas.

$\mathrm{Na}$ tentativa de transformar doutrinas pedagógicas em orientações práticas para o ensino, os herbartianos privilegiaram os princípios de Herbart mais relacionados ao método de ensino dando destaque, sobretudo, aos cinco passos de Rein, isto é, preparação, apresentação, associação, generalização e aplicação. Em realidade o herbartianismo oferecia a resposta para a questão o que e como ensinar; questão 
enfrentada pelo próprio Herbart: Como ensinar os professores a como ensinar? Os passos, portanto, consistiam em uma resposta clara e aplicável ao planejamento e aos programas de ensino.

Embora Herbart não tenha dado tanta ênfase aos conceitos de concentração e correlação de estudos, estes termos ganharam relevância no debate sobre currículo nos Estados Unidos. A exigência da correlação não era apenas administrativa e pedagógica, mas fisiológica: o princípio da época cultural atrelava-se aos princípios da apercepção desenvolvimental. Na opinião de Baker (2001), a recepção da correlação de estudos pelos herbartianos norte-americanos pode ser entendida, também, como parte de uma mudança de ênfase das disciplinas para o método. A forma peculiar pela qual se operou o deslocamento do método intuitivo para a moderna pedagogia nos Estados Unidos instiga a releitura sobre a circulação e a recepção do pensamento pedagógico nesse país e o sentido do que em muitos lugares tem sido denominado de pedagogia tradicional.

Em realidade, a questão não pode ser vista como uma oposição entre conteúdo e método de ensino. Da perspectiva da racionalização curricular a ampliação dos programas era um dado irrefutável. Cabia, portanto, a regulação dessa seleção cultural pelo método. Dessa forma, a questão de como ensinar deve ser vista como mais uma tecnologia de governo do professor e da criança. As mais contundentes defesas da criança no centro da instrução não abdicaram da regulação da prática educativa.

\section{A criança e o currículo na alquimia curricular}

Enquanto os herbartianos insistiam nos conceitos de correlação e concentração na organização dos programas de ensino, outras posições conflitantes mobilizaram o debate sobre a reconstrução do currículo nos Estados Unidos no final do século 19, especialmente as posições de Stanley Hall e John Dewey.

O movimento Child-study liderado por Granville Stanley Hall, por exemplo, enfatizou a orientação do currículo em torno da natureza e das necessidades da criança. Tal premissa não era de fato original, mas o modo como os adeptos do movimento lidaram com a pedagogia científica inscreveu a criança e o currículo em novas concepções que tiveram importantes desdobramentos na história educacional norte-americana. $O$ movimento Child-study surgiu na Inglaterra e na Alemanha, no final do século 19, e floresceu nos Estados Unidos na década de 1890 e na primeira década do século 20. Apesar das divergências internas dentro do movimento, tinha como pressuposto básico o estudo minucioso da criança de forma que o currículo pudesse ser construído em relação à natureza do desenvolvimento infantil.

Embora influenciado parcialmente pelo pensamento de Herbart, o Child-study acabou constituindo-se em uma tendência diferenciada do herbartianismo rivalizando com ele na popularidade pedagógica. Como assinala Baker (2001), esse movimento foi o primeiro a defender de forma sistemática uma reforma da escola pública americana com base no ensino centrado na criança ou sobre a criança.

O conhecimento produzido sobre as crianças visava a inscrever o desenvolvimento numa rede disciplinar. O conceito de desenvolvimento estava relacionado à discussão sobre raça e eugenia e a noções de civilidade e degeneração. Com base nos dados colhidos nos questionários os pesquisadores publicavam os resultados juntamente com uma lista de generalizações ou implicações pedagógicas. Dessa maneira, além de 
oferecer uma fundamentação teórica científica, o movimento pôde disseminar técnicas de ensino e recomendações para a organização das escolas, o que explicaria a popularidade do movimento entre os professores.

Segundo afirmação de Baker (2001), no final do século 19 os termos Nova Psicologia Científica, Nova Psicologia e Educação Nova eram frequentemente utilizados como sinônimos nos periódicos educacionais norte-americanos. A Psicologia e a Educação consolidaram-se como campos profissionais inseparáveis.

Em relação ao currículo a Psicologia passou a oferecer legitimidade científica para a consideração do desenvolvimento infantil na ordenação curricular. Em realidade, o movimento Estudo da Criança radicalizou a ideia de um currículo em harmonia com os reais interesses e necessidades da criança, posição duramente criticada por John Dewey cuja posição foi pormenorizadamente explicitada no livro The child and the curriculum publicado por esse autor em 1902, no calor do debate entre os herbartianos e os partidários do Estudo da Criança nos Estados Unidos.

A consideração do problema em si é reveladora do tipo de discussão que caracterizou a disputa sobre o currículo da escola elementar nesse país, na transição do século 19 para o século 20. De um lado, dizia Dewey, estava a criança, ser em desenvolvimento, vivendo em um mundo de experiências diretas e imediatas. Do outro lado o mundo do adulto, logicamente organizado e o conhecimento fragmentado em matérias escolares. O dualismo podia ser visto também na oposição predominante no debate da época entre o aspecto psicológico - o desenvolvimento infantil - e o aspecto lógico - as disciplinas escolares.

Tal dualidade manifestava-se em duas concepções opostas: os que defendiam as disciplinas como eixo de organização do currículo e os que defendiam o currículo centrado na criança, especialmente os partidários do movimento Estudo da Criança.

$\mathrm{Na}$ opinião de John Dewey os primeiros desconsideravam as características da criança e fundamentavam os estudos no universo objetivo de verdades, leis e ordem dadas pelo conhecimento. Estabeleciam, pois, uma sequência arbitrária, subdividiam tópicos em unidades, estas em lições e cada lição em um fato específico. Por outro lado, para o segundo grupo, a criança era o ponto de partida, o centro, o fim. Desse ponto de vista, os conteúdos de ensino não tinham tanta relevância, eles estavam submetidos ao desenvolvimento das crianças e eram vistos como instrumentos para servirem às necessidades desse crescimento. Era a criança, portanto, que determinaria o currículo.

As duas posições, segundo John Dewey, opunham o aspecto lógico ao aspecto psicológico. Era preciso, portanto, repor o problema de forma correta, isto é, reconstruí-lo de tal modo que esta oposição desaparecesse.

Como assinala Kliebard (1995), a chave do problema, para Dewey, estava no conceito de experiência. A função do currículo era mover-se ao longo de um ponto indefinido, imediato e caótico tomando a experiência integral da criança indo então para um ponto definido, ou seja, a experiência logicamente organizada, abstrata e classificada do adulto. Em outros termos, os aspectos lógicos e psicológicos eram mutuamente dependentes: 
Uma afirmação psicológica da experiência segue o crescimento atual da criança; ele é histórico, ele denota o passo atual alcançado, o tortuoso e incerto, assim como o eficiente e bem sucedido. O ponto de vista lógico, por outro lado, assume que o desenvolvimento alcançou certo estágio positivo de realização. Ele sintetiza os arranjos, e, dessa maneira, separa os resultados alcançados dos passos atuais a partir dos quais eles foram auferidos em primeira instância. (Dewey, 1902, p. 19)

Dewey não via uma oposição entre a criança e o currículo, mas defendia uma forma diferente de considerar a relação e o debate. As considerações desse autor em The child and the curriculum advinham, em parte, de sua experiência no laboratório-escola da Universidade de Chicago. ${ }^{7}$

Nessa escola Dewey buscou reconstruir o currículo do ensino elementar aplicando suas formulações educacionais. Para Kliebard (1995), assim como Stanley Hall e os herbartianos, o currículo da Dewey School consistia em uma interpretação do princípio de Herbart segundo o qual a ontogênese recapitulava a filogênese. No entanto, Dewey deu uma interpretação própria à recapitulação entendendo-a não no sentido dos estágios históricos, mas baseada na evolução das atividades sociais básicas. Tal princípio era visto por Dewey como elo entre os vários componentes do currículo possibilitando, dessa forma, um tipo de unidade que faltava nos programas de ensino vigentes e naqueles propostos por William Harris no relatório do Committee of Fifteen em 1895.

Durante o período em que John Dewey esteve na Universidade de Chicago (18941904), por diversas vezes manifestou sua opinião em relação ao debate curricular em voga. Em relação aos humanistas, especialmente William Harris, Dewey criticava a forma pela qual este educador defendia a centralidade das disciplinas escolares sem respeitar a forma como a criança via o mundo e a relação entre o conhecimento e os propósitos humanos. Em relação aos herbartianos criticava a falta de relação entre as matérias e a falta de interesse que os assuntos selecionados teriam para as crianças.

\section{Considerações finais}

O debate travado pelos educadores norte-americanos, na transição do século 19 para o século 20, sobre a criança e o currículo revela o conflituoso processo de renovação educacional ocorrido nos Estados Unidos nesse período. Longe de constituir um movimento unificado, a denominada educação nova, envolveu diferentes posições e divergências inconciliáveis.

O currículo tornou-se texto e pretexto para propostas de controle e direcionamento da educação norte-americana. Em torno da seleção, distribuição e ordenamento dos conteúdos e da definição sobre métodos de ensino, emergiram diferentes teorias pedagógicas fundamentadas em distintas posições políticas. Uma das consequências desse efervescente debate foi a autonomização do campo do currículo como área de estudo específica, especialmente com a emergência e consolidação no cenário educacional norte-americano do movimento da eficiência social. John Franklin Bobbitt, um dos principais nomes vinculados a esse movimento, com base nos estudos sociológicos de Edward A. Ross e nas ideias da administração científica de Taylor, deixou de lado a centralidade da criança na discussão sobre currículo e deu ênfase aos aspectos

\footnotetext{
${ }^{7}$ O público brasileiro pode encontrar uma análise detalhada dessa experiência em Valdemarin (2010). Hist. Educ. [Online] Porto Alegre v. 20 n. 48 Jan./abr., 2016 p. $35-53$
} 
administrativos do currículo como a otimização do espaço escolar, a aplicação dos princípios da administração científica à educação, a busca da eficiência no ensino e na aprendizagem e a defesa de um currículo diferenciado para diferentes grupos de alunos. ${ }^{8}$

A ampliação do programa do ensino primário com a inclusão de novas matérias como História, Geografia, Ciências Físicas e Naturais, Desenho Geométrico, Música, Geometria, Aritmética, Educação Física, Trabalhos Manuais e Instrução Moral e Cívica, para além do ensino ordinário da leitura, da Gramática, do Cálculo e da instrução religiosa buscou adaptar a escola primária às exigências da formação do homem moderno, portador de uma visão mais racional do mundo e dos valores da modernidade.

Esse enriquecimento da cultura escolar ocorreu concomitante a ampla disseminação da escola primária pública redundando em problemas práticos de organização e funcionamento das escolas. O problema não se restringia à seleção dos conteúdos a ensinar, mas principalmente como ordenar e distribuir esses conteúdos tornando o sistema educacional mais eficaz e eficiente. Vários educadores norte-americanos buscaram equacionar esse desafio problematizando a questão da organização do currículo. Francis Parker e os herbartianos desenvolveram uma fértil reflexão sobre a concentração e correlação das matérias, enquanto os partidários do Child-study e John Dewey postularam a centralidade da criança como critério para a organização curricular.

As batalhas pelo currículo nos Estados Unidos, tal como sugere Kliebard (1995), são pouco conhecidas pelo público acadêmico brasileiro. Revisitar a temática implica reconsiderar as interpretações correntes no Brasil sobre a História do Currículo como campo de conhecimento indo além das obras de Franklim Bobbit e retrocedendo ao efervescente debate instaurado no final do século 19. A discussão sobre concentração e correlação das matérias assinala a emergência de um tema que se tornou recorrente na educação em âmbito internacional no decorrer do século 20, isto é, a articulação imprescindível entre as disciplinas curriculares. As posições contrastantes nesse debate nos Estados Unidos mostra como as disputas pela educação nova pôs a transmissão dos saberes escolares no centro do debate, fazendo do currículo não uma questão menor de administração do ensino, mas como fundamento do debate pedagógico.

A historiografia da educação brasileira tem apontado a educação norte-americana como referência para o país em diferentes momentos históricos. Conhecer, portanto, a história da educação dos Estados Unidos é importante para se problematizar o argumento estrangeiro e a circulação e apropriação de modelos educacionais no Brasil. A propósito, vários aspectos podem ser apontados, mas destacamos dois significativos sublinhados neste texto. Primeiro, a seleção cultural para os programas do ensino primário, assim como a ordenação do currículo, foi um processo contestado o que nos permite refletir sobre a referência dos Estados Unidos na configuração do ensino primário brasileiro no final do século 19. Em segundo lugar, o herbartianismo, apesar de ter durado relativamente pouco na educação norte-americana, esteve associado nesse país às

${ }^{8}$ Em 1918, John Franklin Bobbitt publicou o livro intitulado The curriculum considerado a primeira obra específica sobre o tema, no qual expôs os princípios da perspectiva científica na elaboração de currículos. Em 1924, o mesmo autor publicou How to make a curriculum, outro importante livro de configuração dos estudos do currículo nos Estados Unidos. 
propostas de inovação educacional sugerindo análises mais complexas sobre a circulação e recepção do pensamento de Herbart em outros países, para além da oposição fácil entre escola tradicional e escola nova.

Em síntese, os estudos históricos sobre a educação nos Estados Unidos têm posto em relevo o quadro multifacetário da renovação educacional experienciada por esse país, no final do século 19 e início do século 20. Alguns autores, como Cuban (1984) e Tyack e Cuban (1995), têm chamado a atenção para a situação diversa das escolas públicas norte-americanas em relação à inovação educacional. Nesse sentido, esses autores têm indagado em que medida as reformas educacionais levadas a termo no país e as novas proposições pedagógicas atravessaram os muros das escolas e transformaram o cotidiano do trabalho docente, as atividades dos alunos e as instituições escolares.

Tais problematizações nos impelem ao questionamento sobre os modos pelos quais os educadores dos Estados Unidos construíram uma autoimagem do país como referência de modernização educacional no início do século 20. Nessa direção é interessante refletir sobre o que os educadores estrangeiros incorporaram do debate em circulação naquele país e filtraram como signos da modernidade. Em um caso como no outro, em que pesem as versões históricas construídas pelos pesquisadores no presente, estavam também em questão as possibilidades de abstrair do Novo Mundo, isto é, dos Estados Unidos, as referências do que vinha sendo considerado novo e moderno em educação.

\section{Referências}

BAKER, Bernadette. In perpetual motion: theories of power, educational history, and the child. New York: Peter Lang, 2001.

BUISSON, Ferdinand. Rapport sur l'instruction primaire à L'Exposition Universelle de Philadelphie en 1876, presénté à M. Le Ministre de L'Instruction Publique au nom de la Commission Envoyée par le Ministére à Philadelphie. Paris: Imprimeire Nationale, 1878.

CREMIN, Lawrence. Transformation of the school: progressivism in american education, 1876-1957. New York: Harper and Row, 1961.

CUBAN, Larry. How teachers taught: constancy and change in american classroom, 18901980. New York and London: Longman, 1984.

DE GARMO, Charles. Herbart and the herbartians. New York: Charles Scribner's Sons, 1895.

DEWEY, John. The child and the curriculum. Chicago: University of Chicago Press, 1902.

DUNKEL, Harold B. Herbart and herbartianism: an educational ghost story. Chicago: The University of Chicago Press, 1970.

FINKELSTEIN, Barbara. Governing the young: teacher behavior in popular primary schools in nineteenth century United States. New York: The Falmer Press, 1989.

FRALEY, Angela. Schooling and innovation: the rhetoric and the reality. New York: Tyler Gibson Publishers, 1981.

FRANKLIN, Barry. Building the american community: school curriculum and the search for social control. London: Falmer, 1986.

HIPPEAU, Cèlestin. L'Instruction publique aux États-Unis. Paris: Didier, 1872. 
KAESTLE, Carl. F. The origins of urban school system: New York City, 1750-1850. Harvard University, 1970.

KAESTLE, Carl F. Pillars of republic: common schools and American Society, 1780-1860. New York: Hill and Wang, 1999.

KLIEBARD, Herbert M. Forging the american curriculum: essays in curriculum history and theory. New York: Routledge, 1992.

KLIEBARD, Herbert M. The struggle for the american curriculum (1893-1958). New York: Routledge, 1995.

KRUG, Edward A. The shaping of the american high school (1880-1920). Madison: The University of Wisconsin Press, 1969.

MCMURRY, Charles. A. The elements of general method based on the principles of Herbart. Bloomington: Public-school publishing, 1903.

MCMURRY, Charles A. Course of study in the eight grades. v. 1-2, New York: The Macmillan Company, 1906.

PARKER, Francis W. Talks on teaching. New York: S. Barnes \& Co., 1883.

PARKER, Francis W. Talks on pedagogics: an outline of the theory of concentration. New York/Chicago: E. L. Kellogg \& Co, 1894.

PINAR, Willian F et al. Understanding curriculum: an introduction to the study of historical and contemporary curriculum discourses. New York: Peter Lang, 1995.

POPKEWITZ, T. The formation of school subjects: the struggle for creating an American Institution. New York: Falmer Press, 1987.

TYACK, David B. One best system: a history of american urban education. Cambridge: Harvard University Press, 2000.

TYACK, David; CUBAN, Larry. Tinkering toward utopia: a century of public school reform. Cambridge, Harvard University Press, 1995.

VALDEMARIN, Vera T. História dos métodos e materiais de ensino: a escola nova e seus modos de uso. São Paulo: Cortez, 2010.

WARDE, Mirian Jorge. Americanismo e educação: um ensaio no espelho. São Paulo em Perspectiva (Impresso), São Paulo, v. 14, n. 2, 2000, p. 37-47.

WARDE, Mirian Jorge. Circulação e enredamento de culturas: notas para uma história descomparada da educação. In: CASTRO, Cesar Augusto; CASTELLANOS, Samuel L. V; FELGUEIRAS, Margarida Louro (org.). Escritos de historia da educação: Brasil e Portugal. São Luís: UFMA, 2012, p. 21-34.

ROSA FÁTIMA DE SOUZA é professora na Universidade Estadual Paulista, doutora em Educação pela Universidade de São Paulo.

Endereço: Faculdade de Ciências e Letras da Unesp - Rodovia Araraquara - Jaú, km 1 - 14801-900 - Araraquara - SP - Brasil.

E-mail: rosa@fclar.unesp.br.

Recebido em 3 de julho de 2015.

Aceito em 13 de agosto de 2015. 